G.Z. Brooks MD, Y. Donchin MD, J G. Collins PH D, L.M. Kitahata MD PHD, S.A. Jefferson MD

\title{
Epidural morphine does not affect the duration of action of epidural 2-chloro- procaine following Caesarean section
}

The effect of epidural morphine on the duration of action of epidural 2-chloroprocaine was studied in a doubleblind fashion in 30 patients following elective Caesarean section. When compared to epidurat saline controls $(n=15)$, patients $(n=15$ ) who received epidural morphine (4.0-5.0 mg) did not experience a prolongation or reduction in the duration of the somatic or sympathetic nervous system blockades produced by epidusal 2 -chloro procaine.

\section{Key words}

ANALGESICS: morphine, epidural; ANAESTHESIA: obstetric, Caesarean section; ANAESTHETICS, LOCAL: 2-chloroprocaine; ANAESTHETIC TECHNIQUES: epidural.

2-Chloroprocaine, an ester linked local anaesthetic, has become an important agent in obstetric practice. When administered epidurally, it provides the parturient with effective anaesthesia of last onset. ${ }^{1,2}$ The agent's rapid metabolism by both foetal and maternal plasma pseudocholinesterase ${ }^{3}$ resuits in low cardiac and central nervous system toxicity when compared to the amide-linked local anaesthetics. 2-Chloroprocaine also has been shown to lack

From the Departments of Anesthesiology, Obstetrics and Gynecology and Pharmacology, Yale University School of Medicine, New Haven. Connecticut.

Address correspondence to: Glen Z. Brooks, mD, Dept. of Anesthesiology, Yale University School of Medicine, 333 Cedar Street, New Haven, CT 06510 USA.

CAN ANAESTH SOC J :983/30:6/pp 598-602 any adverse effect on neonatal neurobehaviour, ${ }^{4.5}$ An additional advantage of using epidural 2-chloroprocaine for Caesarean section is the agent's short duration of action, ${ }^{1,2}$ which limits the duration of the patient's somatic and sympathetic nervous system biockades and thus her time at risk for related complications in the postoperative period

While 2-chloroprocaine's short duration of action may result in greater safety by limiting the duration of motor and sympathetic nervous system blockades, it is also associated with an abrupt cessation of analgesia early in the postoperative period. ${ }^{2,6} \mathrm{~A}$ possible way of overcoming this problem is to administer an epidural opioid at the end of the procedure to provide early postoperative analgesia as the anaesthetic effects of epidural 2-chloroprocaine dissipate. It has been well established that intraspinal opiates are capable of producing effective postoperative analgesia. ${ }^{\gamma-10}$ It has also been shown that when administered alone, intraspinal opiates do not produce demonstrable motor, ${ }^{11-13}$ sensory, ${ }^{12-14}$ or sympathetic nervous system blockades. ${ }^{8,12.13 .15}$ Since the synergistic effects of intraspinal opiates with substances such as alpha adrenergic and serotonin agonists have recently been demonstrated, ${ }^{12.16}$ it is important to investigate further the possible effects of epidural opiate interaction with other drugs administered intraspinally.

If epidural narcotic analgesia following Caesarean section could be achieved without prolongation of 2-chloroprocaine's somatic or sympathetic blockades, it would appear that a combination of intraoperative epidural anaesthesia with 2-chloroprocaine and postoperative analgesia with an epidural narcotic would enhance both intraoperative maternal and foetal safety, and postoperative maternal com- 
TABLE Comparisons of epidural morphine and epidural saline groups (mean \pm SEM)

\begin{tabular}{|c|c|c|c|}
\hline$n$ & $\begin{array}{l}\text { Epidural morphine } \\
15\end{array}$ & $\begin{array}{l}\text { Epidural saline } \\
15\end{array}$ & Significance \\
\hline Age (years) & $29.33 \pm 1.52$ & $28.40 \pm 0.85$ & NS* \\
\hline Height $(\mathrm{cm})$ & $161.66 \pm 1.90$ & $161.93 \pm 2.10$ & NS \\
\hline Weight (kg) & $72.72 \pm 3.50$ & $71.98 \pm 3.55$ & NS \\
\hline $\begin{array}{l}\text { Time from last 2-CLPt to study } \\
\text { dnug injection (mins) }\end{array}$ & $18.00 \pm 0.82$ & $16.67 \pm 1.26$ & NS \\
\hline
\end{tabular}

* Not significant, $\mathrm{p}>0.05$.

$\nmid$ 2-chloroprocaine.

fort without delaying her return to physiologic homeostasis. Therefore, we chose to investigate the cffect of epidural morphine on the duration of motor, sensory and sympathetic nervous system blockades following epidural 2-chloroprocaine.

\section{Methods}

Thirty-two otherwise healthy patients scheduled for elective repeat Caesarean section were selected for this study. The study was approved by the Human lnvestigation Committee of Yale University School of Medicine, and informed written consent was obtained from each patient. All patients requested lumbar epidural anaesthesia for their Caesarean sections. Patients received neither narcotic nor psychotropic premedication. Upon entering the operating room, baseline skin temperatures were measured on the dorsa of each patient's feet with a "Tele-Thermometer" skin temperature sensor (YelJow Springs Instrumentation Co., Inc.). Epidural anaesthesia was then performed with the patient in the left latcral decubitus position. Following necdle insertion at the L-2,3 interspace, an epidural catheter was advanced $2 \mathrm{~cm}$ cephalad. Following test dose injections, patients were turned supine with adequate left uterine displacement using a blanket roll, and the remainder of the three per cent 2-chloroprocaine dose was administered. Reinforcing doses were administered at approximately 40 -minute intervals. The volumes of the initial and reinforcing doses of three per cent 2-chloroprocaine were adequate to achieve and maintain T-4 level anaesthesia. Two patients required intraoperative narcotic supplementation of their epidural anaesthetic and wcre climinated from the study. The remaining 30 study patients received no intraoperative narcotic.

During skin closure, the study drug, prepared and randomized by the hospital pharmacy in a double blind fashion, was injected through the epidural catheter. The study drug syringes appeared identical and contained either $10.0 \mathrm{ml}$ of preservative free normal saline, or $5.0 \mathrm{mg}$ of morphine sulfate powder dissolved in and diluted to $10.0 \mathrm{ml}$ with preservative free normal saline $(0.5 \mathrm{mg}$ of morphine per $\mathrm{ml}$ ). The volume of study drug solution injected $(8-10 \mathrm{ml})$ was determincd by each patient's height. Following injections of the study drug solution, the epidural catheters were flushed with $2.0 \mathrm{ml}$ of preservative free normal saline and then removed. All patients were nursed in the semi-recumbent position in the recovery room and on the postpartum floor for at least 12 hours postoperatively.

The duration of the somatic and sympathetic blocks produced by 2-chloroprocaine following the study drug injection were determined as follows. Motor block was considered terminated when the patient could straight leg-raise to a height of $15 \mathrm{~cm}$ above the bed. Sensory block was considered terminated when the patient could appreciate sharp pin prick on her anterior thighs. Sympathetic blockade was considered terminated when the skin temperature on the dorsa of the feet returned to within $1^{\circ} \mathrm{C}$ of baseline values.

Following completion of the study the pharmacy code was broken and the data analyzed. Statistical significance was determined using the Student's t-test.

\section{Results}

There was no significant ( $\mathrm{p}>0.05$ ) difference between the epidural morphine group and the epidural saline control group with respect to age, height or weight (Table). Times from the last 2-chloroprocaine injections to the study drug injections also were not significantly different. 


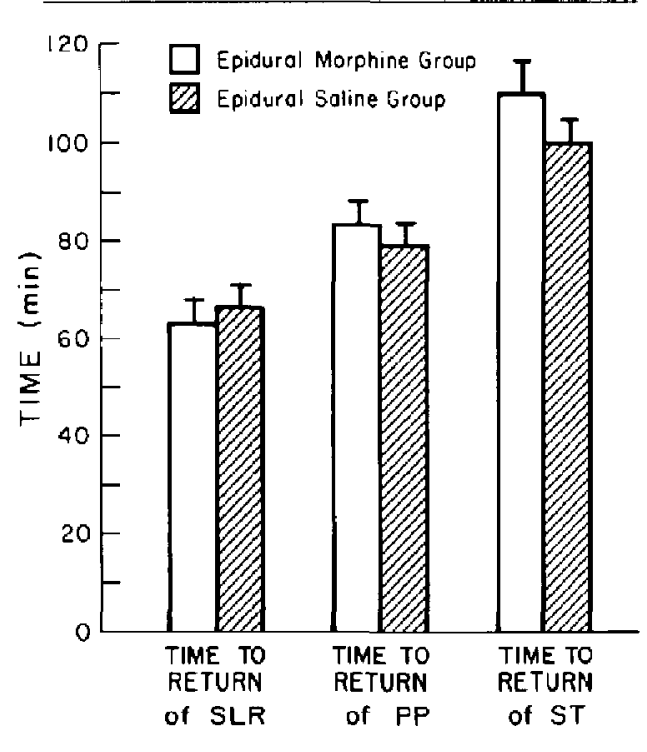

FIGURE Time in minutes following the epidural study drug administration until the return of the patient's ability to straight leg raise (SLR), appreciate pin prick (PP) on her anterior thighs, and experience a return of skin temperature (ST) on the dorsa of her leet to within $1^{\circ} \mathrm{C}$ of preanaesthetic temperatures. There was no significant $(p>0.05)$ difference in recovery times between the epidural morphine group and the epidural saline group.

An analysis of mean recovery times indicated that patients who received epidural morphine did not experience a significant prolongation or reduction in the duration of the motor, sensory or sympathetic blockades produced by epidural 2chloroprocaine (Figure).

\section{Discussion}

We chose 2-chloroprocaine as the local anaesthetic agent for our Caesarean section patients because of the maternal, foetal and neonatal safety associated with its proper administration. Rapid metabolism by plasma pseudocholinesterase ${ }^{3}$ limits the potential central nervous system and cardiovaseular toxicity of drug taken up by or inadvertently injected into the epidural venous plexus. This degree of safety is not found with the more potent hepatically metabolized amide-type local anaesthetic agents. ${ }^{17.18} 2$-Chloroprocaine's short dura- tion of action also makes it an attractive agent when prolonged postoperative motor and sympathetic blockades are not desired.

Following reports in 1980 of four female patients who sustained prolonged sensory/motor deficits following the accidental subarachnoid injection of large volumes of 2-chloroprocaine intended for epidural administration, ${ }^{19.20}$ controversy has surrounded the drug's use. To date, the results of animal studies investigating the issue of 2-chloroprocaine and neurotoxicity have been contradictory. ${ }^{21}$ Because of 2-chloroprocaine's favourable physiochemical properties, we have continued to administer it epidurally employing a careful technique which combines incremental test doses with a slow titration of the agent to the desired dermatomal level of anaesthesia.

Patients who received epidural morphine did not experience a prolongation or reduction in the duration of the somatic or sympathetic nervous system blockades produced by the final dose of epidural 2-chloroprocaine. Since the completion of this study, Carmichael et al. ${ }^{10}$ have published data which also support the lack of a synergistic or antagonistic effect of epidural morphine on the somatic blockade produced by an epidurally administered local anaesthetic (carbonated lidocaine). This implics that intraspinal narcotics do not interact with local anaesthetic agents to alter their biological activity at local anaesthetic receptor sites.

Epidural morphine's failure to affect the duration of the conduction blockade produced by epidural 2-chloroprocaine suggests a benefit of postoperative epidural narcotic analgesia when compared to the analgesia produced by the continued use of an epidural local anaesthetic. By avoiding prolongation of motor block, the risk of developing deep vein thrombosis can be minimized. Delays in recovery room discharge can be avoided, and earlier ambulation also is possible. Because postoperative epidural opiates appear to have no effect on the duration of the chemical sympathectomy produced by epidural local anaesthetics, the patient's time at risk for hypotension is not exaggerated.

Our patients did not experience any serious side effects following epidural morphine administration. Postoperative analgesia with mixed opiate receptor agonists, such as morphine, has been associated with a small but finite incidence of life threatening complications such as delayed respiratory depres- 
sion. The future of safe intrasinal opiate analgesia lies in the development of opiates with high lipid solubility, a property which encourages rapid cord uptake and a limited segmental spread, ${ }^{22}$ and/or the development of receptor specific opiates, ${ }^{13.23}$ which will produce analgesia without concomitant respiratory opiate receptor agonism.

We conclude that epidural morphine does not affect the duration of the somatic or sympathetic nervous system blockades produced by epidural 2-chloroprocaine.

\section{References}

1 Allen $P R$, Johnson $R W$. Extradural analgesia in labour. A comparison of 2-chloroprocaine hydrochloride and bupivacaine hydrochloride. Anaesthesia 1979; 34: 839-43.

2 Datta S, Corke BC, Alper MH, Brown WU, Ostheimer $G W$, Weiss $J B$. Epidural anesthesia and Cesarean section: A comparison of bupivacaine, chloroprocaine, and etidocaine. Ancsthesiology 1980; $52: 48-51$.

$3 O^{\prime}$ Brien JE, Abbey V, Hinsvark O, Perel J, Finster $M$. Metabolism and measurement of 2-chloroprocaine, an ester-type anesthetic. J Pharmaceut Sci 1979; $68: 75-8$

4 Hodgkinson R, Marx GF, Kim SS, Miclat NM. Neonatal neurobehavioral tests following vaginal delivery under ketamine, thiopental and extradural anesthesia. Anesth Analg 1977; 56: 548-53.

5 Abboud TK, Wiliams $V$, Miller $F$, et al. Comparative fetal, maternal, and neonatal responses following epidural analgesia with bupivacaine, chloroprocaine and lidocaine. (Abst.) Anesthesiology 1981; 55: A315.

6 Cohen SE, Wyner J, Gregory PB. Postcesarean section narcotic requirements following epidural anesthesia with bupivacaine and chloroprocaine. Regional Anesth 1980; 5: 15-6.

7 Bromage $P R$, Camporesi $E$, Chestnut D. Epidural narcotics for postoperative analgesia. Anesth Analg 1980; 59: 473-5.

8 Rawai N, Sjöstrand $U$, Dahlström B. Postoperative pain relief by epidural morphine. Anesth Analg 1981; 60: $726-31$.

9 Hughes SC, Rosen MA, Shnider SM, Norton $M$, Curtis $J D$. Epidural morphine for the relief of postoperative pain after Cesarean section. (Abst.) Anesth Analg 1982; 61: 190-1.
10 Carmichael FJ, Rolbin SH, Hew EM. Epidural morphine for analgesia after Caesarcan section. Can Anaesth Soc J 1982; 29: 359-63.

11 Yaksh TL, Rudy TA. Studies on the direct spinal action of narcotics in the production of analgesia in the rat. J Pharmacol Exp Ther 1977; 202: 411-28.

12 Yoksh TL, Reddy SVR. Studies in the primate on the analgesic effects associated with intrathecal actions of opiates, $\alpha$-adrenergic agonists and baclofen. Anesthesiology 1981; 54: 451-67.

13 Yaksh TL. Spinal opiate analgesia: Characteristics and principles of action. Pain 1981; 11: 293-346.

14 Torda TA, Pybus DA, Liberman H, Clark M, Crawford $M$. An experimental comparison of epidural and intramuscular morphine. Br J Anaesth 1980; 52: 939-43.

15 Cousins $M J$, Mather LE, Glynn CJ, Wilson PR Graham JR. Selective spinal analgesia. Lancet 1979; 1: $1141-2$

16 Karoum F, Commissiong $J$, Wyat RJ. Effects of morphine on norepinephrine turnover in various functional regions of rat spinal cord. Biochem Pharmacol 1982; 31:3141-3.

17 Albright GA. Cardiac arrest following regional anesthesia with etidocaine or bupivacaine. Anesthesiology 1979; 51: 285-6.

18 Morishima HO, Pedersen H, Finster M, Feldman $H S$, Covino $B G$. Etidocaine toxicity in the adult, newborn, and fetal sheep. Anesthesiology 1983; 58 : $342-6$.

19 Ravindran RJ, Bond VK, Tasch MD, Gupta CD, Iverssen TC. Prolonged neural blockade following regional analgesia with 2-chloroprocaine. Anesth Analg 1980; 59: 447-57.

20 Reisner LS, Hochman BN, Plumer MH. Persistent neurologic deficit and adhesive arachnoiditis following intrathecal 2-chloroprocaine injection. Ancsth Analg 1980; 59: 452-4.

21 Covino BG. Potential neurotoxicity of local anaesthetic agents. Can Anaesth Soc J 1983; 30: 111-6.

22 Bromage $P R$. The price of intraspinal narcotic analgesia: Basic constraints. Anesth Analg 1981; 60: 461-3.

23 Freye E, Hartung E, Schenk GK. Bremazocine: An opiate that induces sedation and analgesia without respiratory depression. Anesth Analg 1983; 62 : 484-8. 


\section{Résumé}

On a effecrué une étude à double-insu pour évaluer l'effet de la morphine par voie péridurale sur la durée d'action de la 2-chloroprocaïre chez 30 patientes après césarienne élective.

Lorsque comparé avec le groupe contröle $(N=15)$ qui avait reçu du soluté par voie péridurale, le groupe ayant reçu de la morphine $(N=15)$ n'a montré ni prolonga. tion, ni réduction des effets somatiques ou des effets sur le système nerveux sympathique induirs par la 2-chloroprocaine. 